\title{
PONTOS PARA UMA DISCUSSÃO OPERACIONAL SOBRE POLÍTICAS CULTURAIS (LOCAIS)
}

\author{
Natália Azevedo \\ Instituto de Sociologia da Universidade do Porto, Portugal
}

\begin{abstract}
Resumo: $\mathrm{O}$ universo que designamos como políticas culturais mantém a sua centralidade no campo analítico e social, seja ele europeu, nacional ou regional/local. Enquanto propostas de leitura e de intervenção, as políticas culturais são universos de projeto que nos permitem desenhar e concretizar dois parâmetros de uma mesma questão: as práticas de cidadania ativa na relação com as culturas e as artes; e a avaliação sustentada da maior ou menor distância entre os pressupostos de atuação delimitados e as práticas sociais de criação, mediação e receção culturais. Num outro sentido, e em salvaguarda dessa questão central, permitem-nos averiguar até que ponto as práticas culturais e artísticas dos diferentes atores sociais - sejam criadores e políticos, sejam mediadores e recetores - fundamentam um saber viver situado (porque inscrito em territórios físicos e sociais) das culturas e das artes. No contexto de final da primeira década do século XXI, as iniciativas municipais dos últimos 15 anos continuam a suscitar perplexidade quando entendidas como práticas políticas de democratização cultural e artística dos tecidos sociais locais. Nada melhor do que questionar tais modalidades de conceção e intervenção por via de um esforço ainda algo distante: observatórios regionais/locais de avaliação e intervenção.
\end{abstract}

Palavras-chave: políticas culturais municipais; observatórios culturais; intervenção cultural e artística.

\section{Ponto 1.}

Desenhar uma relação possível entre as ciências sociais, no caso a sociologia, e o espaço público, quer quanto aos modos de diagnóstico da realidade social contemporânea, quer quanto à síntese refletida sobre os instrumentos operatórios de leitura e intervenção nos espaços sociais, tem sido uma das nossas aspirações analíticas. Mais ainda quando a nossa pesquisa sociológica tem incidido sobre um objeto teórico e empírico peculiar: as políticas culturais municipais, no caso dos concelhos da Área Metropolitana do Porto (AMP). O destaque tem sido o conjunto de concelhos da AMP, com um referencial empírico de 9 concelhos que, entre 1991 e 2004, constituíam o território metropolitano: Espinho, Gondomar, Maia, Matosinhos, Porto, Póvoa de Varzim, Valongo, Vila do Conde e Vila Nova de Gaia. Nos últimos trabalhos que 
realizámos (Azevedo, 2014)ํㅜㄹ configurámos o objeto para além dos limites temporais e jurídicos que o definiam e anotámos o seguinte: ao longo da década de 1990, e com tempos políticos e sociais diferenciados de afirmação, as políticas culturais autárquicas institucionalizaram-se com duas matrizes básicas - a construção e a dinamização de equipamentos culturais municipais e a criação de uma oferta cultural local.

O universo que designamos como políticas culturais mantém a sua centralidade no campo analítico e social, seja ele europeu, nacional ou regional/local. Enquanto propostas de leitura e de intervenção, as políticas culturais continuam a ser universos de projeto e de intervenção que nos permitem desenhar e concretizar dois parâmetros de uma mesma questão: as práticas de cidadania ativa na relação com as culturas e as artes; e a avaliação sustentada da maior ou menor distância entre os pressupostos de atuação delimitados e as práticas sociais de criação, mediação e receção culturais. Num outro sentido, e em salvaguarda dessa questão central, permitem-nos averiguar até que ponto as práticas culturais e artísticas dos diferentes atores sociais - sejam criadores e políticos, sejam mediadores e recetores - fundamentam um saber viver situado (porque inscrito em territórios físicos e sociais) das culturas e das artes.

Nesse cenário crescente de afirmação das políticas culturais, as cidades foram entendidas como territórios privilegiados para a dinamização cultural e turística por potenciarem sinergias económicas e sociais locais. Entre a centralidade funcional do Porto e as centralidades difusas e alternativas dos concelhos contíguos, que entre 1990 e 2004 definiram os municípios do território metropolitano, a cultura - entendida no vasto leque de representações políticas e simbólicas - deixou de ser um não-lugar político e sedimentou-se, ainda que com picos variáveis, como um dos vetores transversais dos projetos locais de desenvolvimento.

Quando entre fevereiro de 2002 e julho de 2006 enquadrámos um projeto de investigação nos concelhos da AMP com o apoio da Fundação para a Ciência e a Tecnologia $(\mathrm{FCT})^{2}$, os contextos políticos locais e supramunicipais potenciavam dinâmicas culturais e turísticas com características peculiares. Por outro lado, e em articulação com a dimensão turística dos projetos políticos municipais, a realidade cultural e artística dos municípios exigia-nos partir do pressuposto que seria possível

\footnotetext{
${ }^{1}$ Estudo sociológico que apresenta em formato livro uma versão selecionada da dissertação de doutoramento em sociologia apresentada pela autora em 2007 na Faculdade de Letras da Universidade do Porto (FLUP) e intitulada Políticas culturais, turismo e desenvolvimento local na Área Metropolitana do Porto - um estudo de caso (Azevedo, 2007). Encontra-se também disponível em http://ler.letras.up.pt/site/default.aspx?qry=ido6id1203\&sum=sim (formato digital).

2 Projeto POCTI/SOC/39803/2001 - Culturas urbanas, turismo e desenvolvimento local na Área Metropolitana do Porto.
} 
constituir num território metropolitano uma intervenção coesa e articulada. Porém, nas décadas de 1990 e 2000, a AMP pouco mais retratava do que os seus princípios formais quanto à aspiração metropolitana .

\section{Ponto 2.}

Nos meandros dos mundos culturais, as culturas e as artes, com as múltiplas formas de manifestação, sempre nos mobilizaram para certas preocupações analíticas. Interessaram-nos tanto quem protagonizava consumos e procuras culturais (os públicos), como quem construía a oferta e que processos enformavam as representações e as práticas culturais. Porém, cedo concebemos que aquelas não podiam ser desligadas do enfoque nos atores sociais - eleitos locais e atores culturais (locais e regionais) - e do que redimensionavam como pressupostos do desenvolvimento: a oferta cultural municipal e metropolitana e as potencialidades turísticas dos concelhos da AMP.

Temos alguns pontos de chegada, que já não são pontos hipotéticos de pesquisa e de atuação, mas sim pressupostos interiorizados no campo político e resultados sociais das intervenções políticas dos últimos 15 anos: i) a relação entre as políticas culturais e turísticas e os processos do desenvolvimento num contexto territorial local e metropolitano; ii) a articulação reflexiva entre os discursos políticos dos eleitos locais em exercício de funções e as representações de cultura e de turismo cultural como elementos estruturantes dos projetos e das práticas políticas em torno do desenvolvimento; iii) a relativa descoincidência entre os projetos de cidade cultural e turística dos atores políticos locais e os dos atores locais e regionais ligados a organismos de desenvolvimento, de cultura e de turismo; iv) a relativa diferenciação de práticas culturais municipais, com dinâmicas de especialização funcional no conjunto de concelhos da AMP, tanto políticas como culturais; v) e, na sequência de tal, lógicas de afirmação, apropriação e concorrência presentes, quer na fisionomia dos seus espaços e produtos de cultura, quer nas políticas de intervenção cultural e turística; vi) o investimento simbólico e financeiro municipal nas décadas de 1990 e 2000 em equipamentos multifuncionais e programas de oferta cultural municipais e a maior procura dos bens e serviços culturais locais e interconcelhios; e, por último, vii) a dificuldade tanto jurídica como financeira e política em arquitetar uma estratégia metropolitana integrada no campo das culturas, artes e turismo.

\section{Ponto 3.}

Quando reunimos condições para aprofundar os conhecimentos sobre os processos de desenvolvimento e as políticas de turismo nos concelhos que compõem a AMP, 
contribuímos para que os atores do poder político e das instituições culturais e turísticas tenham acesso a levantamentos sincrónicos e diacrónicos de informações. Tais diagnósticos são informações sobre as dinâmicas culturais e turísticas dos concelhos que, dentro dos limites de qualquer exercício analítico, podem sugerir-lhes uma outra fundamentação das políticas culturais e das práticas de planeamento, intervenção e avaliação. Num outro quadrante de discussão, os processos de avaliação ex-ante das políticas culturais municipais podem ser um meio para testar grelhas de observação sistemática (no sentido metodológico mais amplo do termo) sobre os concelhos e a região metropolitana e arquitetar instrumentos de base para a implantação de observatórios locais sobre as realidades culturais e turísticas dos concelhos.

No contexto metropolitano aqui em causa, reconheçamos que é pelo eixo de análise dos públicos culturais, e da procura socialmente segmentada, que a AMP tem sido mais vezes enquadrada. Se transpormos tal eixo de análise para o contexto da sociedade portuguesa, o domínio sociológico do estudo dos públicos da cultura prima por ser necessário: nos últimos 15 anos tem-se configurado o interesse da comunidade de sociólogos pela operacionalização do conceito e pelo alargamento dos conhecimentos empíricos sobre os públicos culturais. Tal tem exigido a fragmentação científica das dimensões de análise e a escolha de objetos empíricos particulares: atendendo ora aos eventos, ora às instituições que os concebem e implementam, ora ainda à delimitação territorial em que se inscrevem. Estes resultados empíricos são contribuições fundamentais do património sociológico português - a legitimidade científica das investigações pela comunidade de pares - mas, igualmente, traduzem a maior sensibilidade dos atores culturais e políticos para o diagnóstico e a avaliação de eventos e de públicos.

O que nos parece crucial no momento presente é não obscurecer as virtualidades analíticas e empíricas que outros concelhos de média dimensão, situados na orla litoral ou na orla do interior português, poderão ter face às cidades centrais de Lisboa e Porto. O protagonismo político e simbólico que alguns destes concelhos/cidades adquiriram nos últimos anos tendem a legitimar a nossa proposta de diagnóstico e avaliação do universo das políticas culturais municipais. Reflexo curioso do vaivém necessário entre a realidade política e cultural destes municípios (objetos sociais que se legitimam por princípios políticos de atuação municipal mais visíveis e coerentes nos princípios dos anos 2000) e os instrumentos teórico-metodológicos disponíveis para o efeito. Por outras palavras, o vaivém desafiador entre a empiria do (e sobre o) social e a teoria sociológica operacionalizável. 
Para esse efeito, mantêm-se como coordenadas de análise possíveis as seguintes: i) o enquadramento institucional das políticas culturais municipais; ii) os princípios e os objetivos; iii) as atividades e as modalidades de atuação; iv) os recursos disponíveis e efetivos; v) os efeitos políticos e sociais da intervenção cultural; vi) as virtualidades e os obstáculos da gestão política e da gestão técnica das iniciativas culturais; vii) a relação com as políticas turísticas da AMP. No caso deste último, viii) a diversidade cultural dos concelhos da AMP e as potencialidades turísticas presentes nos discursos políticos quotidianos e na oferta cultural concelhia; ix) o turismo cultural, na diversidade de sentidos e formas que assume; mas também x) no maior ou menor alcance regional da aspiração simbólica dos atores políticos e económicos quanto à realidade social dos seus concelhos - criar e solidificar a marca Porto e Norte de Portugal.

\section{Ponto 4.}

No verso da questão, e de modo a concretizá-la, apontemos uma sugestão operacional: desenhemos uma estratégia de investigação de ordem intensiva e com preocupações de triangulação de técnicas e de dados. A circularidade metodológica exige o intercâmbio possível entre as virtualidades inscritas nas abordagens qualitativas e quantitativas, ambas atravessadas por pressupostos comparativos. Porém, e sem descurar uma postura de continuum metodológico, o desenho intensivo define-se como a aproximação dominante: analisemos similitudes e diferenças entre políticas culturais municipais e façamos a experiência desse painel por contraste.

As técnicas a contextualizar - na multiplicidade socialmente inscrita das virtualidades analíticas que sugerem e nas circunstâncias de interação de partida - correspondem a tentativas de saturação analítica do objeto. A entrevista, numa feição não estruturada quando sugerida a informantes privilegiados, e com relativa diretividade quando direcionada para a conversação com atores sociais e políticos, é uma tentativa descritiva e analítica face ao objeto em questão. Quando cruzada com outros instrumentos - a observação com fins exploratórios e associada às situações de interação da entrevista, a análise documental de um conjunto de fontes, o inquérito por questionário a públicos emergentes e efetivos e as histórias de vida política, cultural e artística de alguns dos protagonistas do tecido social local - alargam-se os horizontes de leitura das políticas culturais à escala municipal e metropolitana.

$\mathrm{Na}$ relação triangular entre culturas e artes, turismo e desenvolvimento, os vértices reposicionam-se; contudo, ponderamos os dois primeiros como vetores políticos dos planos mais globais do desenvolvimento e que, a priori, estão na origem de uma possível afirmação dos centros urbanos concelhios e da própria AMP. A cultura e o 
turismo são dimensões com lugar sociológico nas problematizações sobre os processos de desenvolvimento e têm lugares políticos nas matrizes sociais de leitura do local e do regional. Quando a há, a hierarquização das prioridades políticas decorre, por um lado, do equilíbrio funcional entre as necessidades do território local e a oferta possível de respostas; por outro, das lógicas de exercício dos poderes político e económico e dos recursos exigíveis. A cultura e o turismo continuam a ser dimensões prioritárias do desenvolvimento num momento em que os trajetos históricos e político-económicos primordiais da qualidade de vida social têm níveis de realização política e de equidade social. Valerá a pena posicionar a centralidade destas questões num cenário em que encontramos uma AMP composta por 17 (diferentes) concelhos, com mandatos políticos autárquicos recentes e com uma marca mais definida quanto a uma região, tanto do ponto de vista político e mediático como social - Porto e Norte de Portugal.

Numa abordagem operacional, justificar-se-á, de igual modo, interpretar as já registadas lógicas de afirmação intraconcelhia, por confronto com os constrangimentos formais e políticos de afirmação interconcelhia e metropolitana. O projeto metropolitano em torno da oferta cultural e das potencialidades turísticas regionais continua a desenhar-se mais como uma aspiração política do que como a possibilidade efetiva de tais práticas políticas.

Aproximemo-nos do figurino sociológico da investigação direcionada para uma prática sustentada - e retenhamos que o nosso campo de possíveis é tão legítimo e limitado quanto outros construídos a partir dos códigos teóricos e metodológicos de leitura científica sobre o social.

\section{Ponto 5.}

O que dizer da centralidade dos anos 1990 e 2000? Os eleitos locais da AMP associam, política e simbolicamente, a cultura e o turismo enquanto vetores transversais aos projetos do desenvolvimento intraconcelhio. As representações políticas e simbólicas que constroem sobre o território metropolitano dimensionam, num painel de cruzamentos intersticiais, princípios de afirmação territorial municipal, de cooperação sectorial entre alguns concelhos e de convergência quanto à natureza da oferta cultural e turística. Por outro lado, protagonizam, enquanto eleitos locais, algumas práticas contrárias aos princípios anteriores: a competitividade intermunicipal; a não articulação política na temporalidade da oferta e na criação e usos dos equipamentos culturais e desportivos; o não planeamento da oferta turística regional; ou a divergência quanto à liderança política do projeto metropolitano e aos equilíbrios possíveis entre as 
necessidades $\mathrm{e}$ as especificidades culturais $\mathrm{e}$ turísticas intraconcelhias $\mathrm{e}$ supramunicipais.

Com a extensão formal da AMP (à data de 2014 com 17 concelhos), como posicionar os discursos políticos e os discursos sobre as práticas políticas? Conseguiremos visualizar os mesmos pontos de convergência dimensionados a uma escala de 9 concelhos? A cultura deixou de ser um não-lugar político e passou a constituir uma prioridade de intervenção, ainda que mais entre aqueles que, face à centralidade funcional do concelho do Porto, mais dificuldades infraestruturais têm. Testemunham-no os programas políticos, os planos e relatórios de atividades das autarquias, as práticas políticas objetivadas pelos próprios eleitos locais, os princípios estratégicos de atuação e as prioridades de investimento político e social. No caso presente, mais do que compreender os diferentes posicionamentos assumidos pela cultura no quadro institucional das autarquias, interessa-nos analisar as temporalidades e os contextos em que adquirem uma centralidade política relativa.

Num universo de 17 concelhos, contrastar e/ou aproximar os percursos políticos desenvolvidos e os cenários culturais locais, tanto na componente da oferta/criação como na da procura/receção, permite-nos compreender os lugares que se vão posicionando nas relações com o centro económico e cultural (o Porto) e com outras extensões territoriais (ora para o litoral, ora para o interior). Como interpretar, nessas temporalidades, as especificidades sociodemográficas, económicas, culturais e turísticas que os redefinem, a reciprocidade da relação com o centro polarizador da região e o estatuto de centralidades alternativas? Por outro lado, as necessidades sociais das comunidades locais traduzem uma outra reflexividade sobre o social que os próprios atores protagonizam. O equilíbrio entre as duas dimensões da relação - as necessidades e potencialidades da vida local inscritas territorialmente e as competências e modos de exercício do poder local - é a matriz transversal às representações dos autarcas sobre a natureza da sua própria prática política e os processos do desenvolvimento concelhio sustentado. Contudo, a cultura mantém-se central nos discursos políticos e sem correspondência com concretizações efetivas ou com tempos políticos e sociais não coincidentes com os das formulações intencionais. Numa AMP a 17 concelhos, torna-se heurística a análise das velocidades concelhias diferentes e dos desencontros entre os dois níveis: o representacional/reflexivo e o da prática. 


\section{Ponto 6.}

Indicadores como os que contemplam a macroestrutura autárquica na relação direta com os serviços culturais autárquicos continuam a primar pela curiosidade factual quando perspetivados nos 17 concelhos. Ainda que tenham sido alvo de um posicionamento organizacional e político mais autónomo, com atribuições, competências, recursos e técnicos próprios, a autonomia efetiva daqueles comporta constrangimentos institucionais e políticos que vale a pena operacionalizar em grelha de observação documental: i) os equilíbrios sectoriais no seio da organização; ii) as representações políticas diferenciadas no seio do município; iii) a maior ou menor legitimidade política e social da intervenção cultural no concelho; iv) as prioridades orçamentais e a hierarquização dos gastos municipais na cultura; v) a composição sociodemográfica das equipas de técnicos dos serviços culturais; vi) a acumulação de pelouros na mesma figura política; vii) os recursos organizacionais (financeiros e técnicos) como peças estruturantes das práticas políticas no campo da oferta cultural municipal.

No mesmo percurso analítico, valerá a pena continuar a discernir, e nessa escala territorial (17 municípios), as representações polissémicas daquilo que constitui a cultura, ou como preferimos designar, as culturas e as artes (os sentidos e campos de possíveis da prática política): viii) o equilíbrio entre modalidades culturais diferentes traços da cultura popular, da cultura erudita e das indústrias culturais); ix) as estratégias de formação de públicos para a cultura erudita e para a produção/criação cultural; x) a ação pedagógica dos projetos e atores culturais envolvidos; xi) o cruzamento entre os níveis de expressão cultural; xii) o investimento político e social nas formas de cultura cultivada e nas manifestações artísticas contemporâneas (pelos municípios); xiii) a reconfiguração das tradições culturais inscritas nas historicidades de cada concelho (pelas associações locais); e xiv) o aumento progressivo dos investimentos financeiros e logísticos na diversidade cultural e artística.

Para além do alargamento dos equipamentos culturais municipais, associado ao dos equipamentos desportivos nos concelhos, destacam-se outros pontos de chegada concelhios e potenciais indicadores de análise da contemporaneidade das políticas culturais municipais: xv) o alargamento das infraestruturas culturais e desportivas e das potencialidades turísticas da oferta cultural e desportiva; xvi) o aparecimento de equipamentos, bens e serviços que se coadunam com a valorização do património arquitetónico urbano; xvii) a territorialização da oferta municipal cultural e desportiva; xviii) a associação entre as manifestações culturais locais e as potencialidades turísticas 
daí advenientes para os concelhos e para a Região do Norte (desde o turismo cultural e o turismo de negócios até ao ecoturismo e ao turismo balnear).

\section{Ponto 7.}

Assinalemos outras convergências interconcelhias, indicadores possíveis da definição e operacionalização das políticas culturais municipais: i) a promoção de eventos culturais com influência supramunicipal (regional, nacional e internacional); ii) a contínua preocupação estratégica com a revitalização do tecido social e do associativismo cultural; iii) o investimento na revitalização e manutenção do património local a partir das possibilidades criadas pelos financiamentos nacionais e comunitários dos últimos anos; iv) a relativa continuidade dos posicionamentos político-partidários municipais, com uma fragmentação das câmaras no binómio socialistas/sociais-democratas; v) a relativa longa duração do exercício do papel político dos autarcas; vi) a criação de uma oferta cultural municipal permanente, a dinamização de uma rede de equipamentos municipais básicos para os usos dos residentes locais e a formação e alargamento dos públicos culturais e artísticos.

Num outro sentido, o dilema principal das políticas culturais atravessa-se na sustentabilidade temporal e estrutural dos processos já expostos. Sem esquecermos que as culturas e as artes se posicionam de modo diferenciado nos discursos e práticas políticas, há distâncias entre os concelhos que traduzem desafios nos modos de perspetivar as políticas culturais no tempo e no espaço e na relação com a endogeneidade e a exogeneidade dos atores, projetos, equipamentos, recursos. Por exemplo: i) a centralidade do Porto quanto à rede de equipamentos culturais que detém, à diversidade e amplitude da oferta cultural municipal e às possibilidades da formação cultural e artística dos atores sociais residentes e não residentes no concelho; ii) as centralidades culturais endógenas dos concelhos limítrofes ao Porto e para usos das comunidades residentes nos municípios; iii) a viabilidade política dos princípios da democratização cultural e da descentralização cultural face à macrocefalia cultural e artística - redimensionada, é certo - que o centro urbano do Porto possui quanto a equipamentos, criadores e públicos. A estratégia global para concretizar um serviço público - neste caso pelo poder local - nas áreas da criação/produção, formação/distribuição/mediação e receção cultural e artística é mais exequível num posicionamento metropolitano, que integre as centralidades culturais difusas dos municípios da AMP.

As políticas culturais municipais consubstanciam-se, do nosso ponto de vista, na base de diagnósticos sistemáticos sobre públicos, tanto na sua configuração sociológica 
como nas condições (espaços, tempos, modalidades) em que se apropriam das manifestações culturais e artísticas. As análises que realizámos até ao momento fazemnos crer que a reflexividade política e social dos autarcas e dos atores culturais e artísticos orienta-se no sentido de perspetivar as políticas culturais a vários níveis: diagnóstico, conceção, implementação e avaliação. Porém, são ainda dimensões por explorar com sistematicidade nas práticas políticas municipais. São variáveis que o poder político local reposiciona à medida que determinados eventos culturais de referência dos concelhos - e registe-se que qualquer um dos concelhos da AMP o tem, ainda que com amplitudes diferentes - se consubstanciam, tanto pela oferta como pelos públicos criados.

\section{Ponto 8.}

De forma a sustentar mais e melhor este pressuposto, configura-se a necessidade de um esforço metropolitano na conceção, implementação e avaliação de uma política cultural conjunta ou, pelo menos, de certas dimensões de uma política cultural supramunicipal: i) a temporalidade da oferta; ii) a criação e dinamização de certos equipamentos e iii) a oferta de certos bens e serviços que, pelo seu âmbito e pelos recursos exigidos, mais e melhor se operacionalizam por via do esforço metropolitano. As políticas culturais locais podem ser concebidas e implementadas em termos metropolitanos. A cultura terá uma expressão maior com uma aproximação entre as políticas e as ações desenvolvidas pelos municípios nestas matérias, de modo estratégico, sistemático, concertado e coordenado. Perante um cenário de não regionalização efetiva do território português, uma das variáveis com acentos particulares nos discursos de alguns dos atores locais, o esforço de viabilizar políticas de concertação metropolitana torna-se, do ponto de vista representacional dos autarcas, pouco possível, quando não, política e institucionalmente, insustentável.

Outros pontos de chegada estruturam o princípio analítico de algum bloqueio político ao desenvolvimento de parcerias municipais conjuntas: i) a competitividade política e cultural entre concelhos e lideranças; ii) a aspiração a uma certa legitimação social e simbólica da centralidade difusa no campo cultural local; iii) os desequilíbrios estruturais significativos quanto à escala dos equipamentos e aos recursos financeiros, técnicos e humanos disponíveis; iv) o posicionamento sempre negociado das prioridades políticas e sociais dos investimentos na cultura face a outras áreas do desenvolvimento; v) as representações negativas dos eleitos locais sobre a viabilidade global do projeto metropolitano. 
Valerá a pena discutir e integrar na análise dos novos concelhos do território metropolitano variáveis cuja resolução implica opções ideológicas, alterações jurídicas e concertações políticas. Que mecanismos de aproximação existem entre as políticas culturais municipais que permitam identidades metropolitanas no exterior? Como contrariar as insuficiências legais do diploma sobre as áreas metropolitanas, a exiguidade dos recursos à escala metropolitana, as prioridades políticas diferenciadas entre os representantes políticos, a falta de visibilidade política e de estrutura organizacional operacional da Junta Metropolitana da AMP ou o estatuto diferenciado que a cultura e o turismo têm, decorrente da sua própria natureza ideológica? Estes últimos são vetores sectoriais das políticas globais do desenvolvimento que só se consubstanciam quando integrados nas lógicas económicas de funcionamento dos mercados e da produção de riqueza. Mas estas, diríamos, também se autossustentam quando em articulação ponderada com os processos culturais e turísticos. A uma escala local e regional, tais reposicionamentos transversais adquirem maior pertinência e viabilidade na articulação entre o local e o global.

\section{Ponto 9.}

Permanecemos com a convicção que a transformação da cidade e do concelho se processa por via da produção/criação cultural e artística e das dinâmicas turísticas. No momento presente, 2014, o Porto enquanto concelho e cidade revigora-se num projeto político que, para além das ressonâncias demagógicas que os faits divers culturais também têm, sugere diferenças de pressupostos e de práticas no campo cultural e artístico local e metropolitano. À luz de uma AMP composta por 17 concelhos - o que, se amplia as possibilidades da oferta e dos usos culturais e artísticos, amplia também as responsabilidades políticas e sociais quanto à sustentabilidade integrada dessa mesma oferta - mantemos como necessários os vetores analíticos partilhados nos pontos anteriores. E acrescentamos o desafio que o duplo papel do sociólogo configura: o do estudo científico dos processos sociais e o da intervenção estruturada e participada sobre essa mesma realidade social.

As políticas culturais fundamentam-se em exercícios sistemáticos de diagnóstico e de avaliação. Daí que, num sentido sociológico, mereça atenção a análise diacrónica da configuração política e social da oferta e da procura culturais à escala dos municípios portugueses, como dos processos de mediação cultural e artística nesses mesmos contextos. Nomeadamente, entre aqueles que, mesmo numa situação de não centralidade territorial - concelhos do interior do continente português - e de não centralidade cultural e turística, direcionaram recursos para a criação de uma oferta 
cultural municipal, dos anos 1990 em diante, e ao abrigo dos programas de financiamento do poder central e comunitários.

Numa segunda perspetiva operacional, de que modo é possível assegurar a sustentabilidade do investimento político e social na área das culturas e das artes, nas suas mais diversas manifestações, à escala local e supramunicipal? A sustentabilidade torna-se viável, em certa medida, desde que se integre, no processo de conceção, implementação e avaliação das políticas culturais e turísticas, o conjunto de instâncias de decisão política, regionais e locais; os agentes económicos e turísticos, públicos e privados; e as instâncias técnicas de atuação. É da articulação horizontal entre, pelo menos, estes três níveis de atuação, posicionada e negociada com as redes locais do associativismo e os agentes da mediação cultural e artística, que as lógicas municipais podem aferir as possibilidades efetivas da sustentabilidade dos seus projetos para os concelhos.

Preocupação política e social dominante no presente entre os municípios e o Estado é a articulação entre a cultura e o turismo, à escala regional, de forma a potenciar sinergias locais e promover práticas de desenvolvimento concertado. Tal pressupõe lógicas de atuação da AMP, e dos concelhos que a compõem, com uma menor conflitualidade político-partidária e uma maior operacionalidade jurídica, organizacional e técnica na conceção, implementação e avaliação dos projetos culturais e turísticos (municipais e metropolitanos).

Mais ainda central, para efeitos de análise operacional, é o plano da relação entre a análise e a ação: como articular, num contexto de exercício do poder político, as lógicas de investigação e as lógicas de intervenção? Como se sustenta a sua pertinência e se viabilizam os diagnósticos dos públicos, dos contextos da oferta e dos modos de procura e de relação com os bens culturais, artísticos e turísticos? $\mathrm{Ou}$, em contrapartida, como conceber e implementar, nos contextos locais, sistemas de avaliação orientada, controlada e sistemática dos projetos, dos processos e dos resultados, tanto no plano da oferta como no da procura cultural, artística e turística?

Do nosso ponto de vista, são vetores de resposta plausíveis a criação de observatórios locais e regionais, a relação com os meios universitários e as instâncias técnicas do território metropolitano, os intercâmbios participados entre poder político, associativismo local e regional, atores de mediação cultural e turística e atores económicos. Estas questões adquirem tanto mais pertinência quanto mais perspetivadas segundo posicionamentos teórico-metodológicos transdisciplinares. Por outro lado, e em sintonia com as respostas cientificamente fundamentadas, são as 
práticas políticas que potenciam as mudanças dos cenários culturais e turísticos municipais. Da consonância participada e plural entre o saber investigar o cultural e o saber intervir politicamente sobre o cultural, poder-se-á, também, (re)construir a cidade, o concelho e a região metropolitana enquanto território de produção e de receção cultural e simbólica.

No contexto de final da primeira década do século XXI, as iniciativas municipais dos últimos 15 anos continuam a suscitar perplexidade quando entendidas como práticas políticas de democratização cultural e artística dos tecidos sociais locais. Como se situarão em 2014 os dois vetores principais destas políticas: a criação de uma rede municipal de equipamentos e a conceção e sustentabilidade de uma oferta cultural municipal? Não estarão dissociados dos sentidos da descentralização e democratização cultural e da formação cultural dos públicos. Porém, valerá a pena questionar tais modalidades de conceção e intervenção por via de um esforço ainda algo distante: observatórios regionais/locais de avaliação e intervenção. Ainda que resolvamos alguns dos desafios enunciados, as políticas culturais serão sempre cenários de espanto quando entendidas como práticas políticas efetivas de democratização e de integração dos tecidos sociais locais e regionais.

\section{Referências bibliográficas}

Azevedo, Natália (2014) Políticas culturais, turismo e desenvolvimento local na Área Metropolitana do Porto: fragmentos de um estudo de caso (1980-2001). Porto: Ed. Afrontamento.

Azevedo, Natália (2007) Políticas culturais, turismo e desenvolvimento local na Área Metropolitana do Porto: um estudo de caso. Porto: Faculdade de Letras da Universidade do Porto.

Natália Azevedo: Professora Auxiliar do Departamento de Sociologia da Faculdade de Letras da Universidade do Porto (FLUP) e Investigadora Integrada do Instituto de Sociologia da UP, linha de investigação Desigualdades, Cultura e Território. Doutora e mestre em Sociologia pela FLUP, tem como áreas privilegiadas de investigação a sociologia da cultura e a sociologia das artes. Desenvolve atividades de pesquisa nos domínios das culturas urbanas, práticas e políticas culturais, desenvolvimento local, turismo cultural e metodologias de investigação, intervenção social e avaliação. Tem exercido funções de consultoria metodológica e de avaliação de projetos de investigação e intervenção no domínio do social e artístico.nazevedo@letras.up.pt 